\title{
Levels of endogenous cytokinins, indole-3-acetic acid and abscisic acid during the cell cycle of synchronized tobacco BY-2 cells
}

\author{
Pascale Redig ${ }^{\mathrm{a}, * *}$, Orit Shaul ${ }^{\mathrm{b}}$, Dirk Inzéb,c, Marc Van Montagu ${ }^{\mathrm{b}}$, Harry Van Onckelen ${ }^{\mathrm{a}, *}$ \\ ${ }^{2}$ Departement Biologie, Universitaire Instelling Antwerpen, Universiteitsplein 1, B-2610 Antwerpen, Belgium \\ ${ }^{\mathrm{b}}$ Laboratorium voor Genetica, Departement Genetica, Flanders Interuniversiteit, Instituut voor Biotechnologie, Universiteit Gent, B-9000 Gent, Belgium \\ ${ }^{c}$ Laboratoire Associé de l'Institut National de la Recherche Agronomique (France), Universiteit Gent, B-9000 Gent, Belgium
}

Received 6 June 1996

\begin{abstract}
Correlation between cell cycle progression and endogenous levels of plant hormones was studied in synchronized tobacco BY-2 cell suspension cultures. Sixteen different cytokinins, indole-3-acetic acid (IAA) and abscisic acid (ABA) were extracted using solid-phase anion exchange chromatography in combination with immunoaffinity purification, and quantified by mass spectrometry. No significant correlation could be identified for IAA and ABA. In contrast, there were sharp peaks in the levels of specific cytokinins (zeatin- and dihydrozeatin-type) at the end of the $S$ phase and during mitosis. The levels of other cytokinins analyzed, including zeatins $N$ - and $O$-glucosides, remained low, suggesting that the increased amounts of their corresponding non-glucosylated form resulted from de novo synthesis. These findings suggest that zeatin- and dihydrozeatintype cytokinins might play a specific regulatory role in the progression of the plant cell cycle. One hypothesis to explain cytokinin action is based on a specific interaction with kinases that regulate cell cycle progression, as has been recently shown for the cytokinin analogue olomoucine.
\end{abstract}

Key words: Cell cycle; Cytokinin; Mass spectrometry; Plant hormone; Synchronization; Tobacco BY-2 cell

\section{Introduction}

The basic mechanism of cell cycle control appears to be conserved among eukaryotes and key regulators such as cyclin-dependent kinases (CDK) and their activating cyclin subunits have also been identified in plants (for a review see [1,2]). Although the yeast, animal, and plant cell cycle share many features, its mode of regulation differs in each type of organ-

\footnotetext{
*Corresponding author. Fax: (32) (3) 8202271

**The two first authors have equally contributed to this work.

Abbreviations: ABA, abscisic acid; CDK, cyclin-dependent kinase; 2,4-D, 2,4-dichlorophenoxyacetic acid; DEAE, diethylaminoethyl; DZ, dihydrozeatin; DZNG, dihydrozeatin- $N$-glucoside; DZMP, dihydrozeatin riboside-5'-monophosphate; DZOG, dihydrozeatin- $O$-glucoside; DZROG, dihydrozeatin riboside- $O$-glucoside; DZR, dihydrozeatin riboside; GC, gas chromatography; gfw, gram fresh weight; $2 \mathrm{iP}$, isopentenyladenine; $2 \mathrm{iP} 9 \mathrm{G}$, isopentenyladenine-9-glucoside; IAA, indole-3-acetic acid; iPMP, isopentenyladenosine-5'-monophosphate; iPNG, isopentenyladenine- $N$-glucoside; $2 \mathrm{iPA}$, isopentenyladenosine; LC, liquid chromatography; MAP, microtubule associating protein; MS, mass spectrometry; RP, reversed phase; SIM, single-ion monitoring; $\mathrm{Z}$, zeatin; $\mathrm{Z9G}$, zeatine-9-glucoside; ZMP, zeatin riboside-5'-monophosphate; $Z N G$, zeatin- $N$-glucoside; ZOG, zeatin- $O$-glucoside; $\mathrm{ZR}$, zeatin riboside; $\mathrm{ZROG}$, zeatin riboside- $O$ glucoside
}

ism. In plants, cell division is influenced by intrinsic developmental programs and by environmental factors, which can both act through regulation of the levels of plant hormones. In particular, the plant hormones auxin and cytokinin have dramatic effects on cell division [3]. Cytokinins were first discovered by their ability to promote plant cell division [4], but by now have been implicated in almost all stages of plant growth and development (for a review see [5]). Similarly, auxins have been shown to be involved in cell division, cell elongation, and cell differentiation [6]. Cytokinins and auxins can interact both synergistically and antagonistically; for example, both are required to stimulate cell division in cultured tobacco pith tissues [7], but oppose each other in the control of shoot and root initiation in tissue cultures and in the maintenance of apical dominance [8]. Based on functional assays, cytokinins were suggested to be involved in the passage through several restriction points of the plant cell cycle [9-11]. There is also evidence for the involvement of other plant hormones, such as abscisic acid [12], gibberellins [13], ethylene [14], and polyamines [15] in the regulation of cell division. Although the effects of phytohormones on plant growth have been studied extensively, not much is known about fluctuations in the levels of endogenous hormones during the cell cycle. Here, we report the analysis of 16 different naturally occurring cytokinins, indole-3-acetic acid (IAA), and abscisic acid (ABA), throughout the cell cycle of synchronized tobacco BY-2 [16] cell suspension cultures. Our findings suggest that specifically zeatin-type (Z-type) cytokinins, and possibly also their dihydro derivatives, might play a regulatory role during the cell cycle.

\section{Material and methods}

\subsection{Chemicals}

All cytokinin-deuterated tracers $\left(\left[{ }^{2} \mathrm{H}_{5}\right]-\mathrm{Z},\left[{ }^{2} \mathrm{H}_{5}\right]-\mathrm{ZR},\left[{ }^{2} \mathrm{H}_{5}\right]-\mathrm{Z} 9 \mathrm{G}\right.$, $\left[{ }^{2} \mathrm{H}_{5}\right]$-ZOG, $\left[{ }^{2} \mathrm{H}_{5}\right]$-ZROG, $\left[{ }^{2} \mathrm{H}_{6}\right]-2 \mathrm{PP},\left[{ }^{2} \mathrm{H}_{6}\right]$-2iPA, $\left[{ }^{2} \mathrm{H}_{6}\right]-2 \mathrm{iP} 9 \mathrm{G},\left[{ }^{2} \mathrm{H}_{3}\right]-$ DZMP) were purchased from Apex (Honiton, UK). $\left.{ }^{18} \mathrm{O}\right]-\mathrm{ABA}$ was prepared according to [17] and $\left[{ }^{13} \mathrm{C}_{6}\right]$-IAA was purchased from Cambridge Isotope Lab (Woburn, MA). Radioactive tracers were obtained from the Institute of Experimental Botany, Isotope Laboratory (Prague, Czech Republic): $\left[2{ }^{3} \mathrm{H}\right]$-(trans)-zeatin riboside $(0.9 \mathrm{Tbq} / \mu \mathrm{mol})$ and $\left[2-{ }^{3} \mathrm{H}\right]$-(trans)-zeatin $(0.9 \mathrm{Tbq} / \mu \mathrm{mol})$. Alkaline phosphatase $(10$ $\mathrm{mg} / \mathrm{ml}, 2500 \mathrm{U} / \mathrm{mg}$, EIA grade) was purchased from BoehringerMannheim (Mannheim, Germany). RP-C18 columns ( $0.5 \mathrm{~g})$ were purchased from Varian (San Fernando, CA) and DEAE Sephadex (A-25) from Pharmacia Biotech (Uppsala, Sweden).

\subsection{Culture maintenance and synchronization}

The Nicotiana tabacum BY-2 cells require the exogenous supplementation of auxin, but not cytokinin, for its growth. The culture was maintained as described [16] by a weekly 70 -fold dilution in modified Linsmaier and Skoog medium supplemented with $0.2 \mathrm{mg} / 1$ of the auxin 2,4-dichlorophenoxyacetic acid (2,4-D). The cells were 
cultured on a rotary shaker at $130 \mathrm{rpm}$ at $27^{\circ} \mathrm{C}$ in the dark. The cultures were synchronized as described by Nagata et al. [16]. Briefly, a stationary culture was diluted 10 -fold in fresh medium supplemented with $5 \mathrm{mg} / \mathrm{l}$ aphidicolin. After $24 \mathrm{~h}$, the drug was removed by extensive washing and the cells were resuspended in fresh medium. Samples of cell culture ( $4 \mathrm{ml}$, corresponding to $\approx 0.25 \mathrm{gfw}$ of cells) were left to sediment on ice, the supernatant was removed completely and re-centrifuged to eliminate remainders of cells, and both the cells and the supernatant were immediately frozen in liquid nitrogen and stored at $-70^{\circ} \mathrm{C}$. To determine the mitotic index, cells were fixed in ethanol/ acetic acid $(3: 1, v / v)$ and stained with $2 \%$ orcein in lactic acid/propionic acid $(1: 1, \mathrm{v} / \mathrm{v})$. Nuclei at late prophase to telophase were scored by microscopic analysis of 300 cells.

\subsection{Extraction and purification of cytokinins, $I A A$, and $A B A$}

Frozen cells $(0.20 .3 \mathrm{~g})$ were extracted overnight at $-20^{\circ} \mathrm{C}$ in $\mathrm{CHCl} / \mathrm{CH}_{3} \mathrm{OH} / \mathrm{H}_{2} \mathrm{O} / \mathrm{HCOOH}(5: 12: 2: 1)$ (Bieleski solvent) [18]. The use of this solvent during the extraction procedure ensured that hydrolysis of the cytokinin nucleotides did not occur. Deuterated cytokinins, $\left[{ }^{18} \mathrm{O}\right]-\mathrm{ABA}$ and $\left[{ }^{13} \mathrm{C}_{6}\right]$-IAA were added as internal standards $\left(50 \mathrm{ng}\right.$ each). After centrifugation $\left(24000 \times \mathrm{g}, 4^{\circ} \mathrm{C}, 20 \mathrm{~min}\right)$, organic solvent from the supernatant was evaporated in vacuo and the $\mathrm{pH}$ of the resulting water phase was adjusted to 7 . This extract was loaded on a combination of a pre-immune serum column, an IAA immunoaffinity column [19] and an ABA immunoaffinity column [20]. The effluent, containing the cytokinins, was then further purified on a combination of a DEAE sephadex ( $2 \mathrm{ml}, \mathrm{HCO}_{3}{ }^{-}$form) and a RP-C18 column. After rinsing the affinity columns with water, the IAA and ABA immunoaffinity columns were eluted with $4 \mathrm{ml}$ of ice-cold $100 \%$ methanol and immediately rinsed with water. The fractions containing IAA and $\mathrm{ABA}$ were dried under vacuum and stored at $-70^{\circ} \mathrm{C}$ until further analysis by GC-MS. After washing the DEAE sephadex and RP-C18 columns with water, the fraction eluting from the RP-C18 column with $10 \mathrm{ml}$ of $80 \%$ methanol contained the cytokinin-free bases, ribosides, and glycosides. The eluate was dried in vacuo to remove the methanol and then applied to a combination of a cytokinin immunoaffinity and a RP-C18 column. The immunoaffinity columns were prepared with monoclonal $\mathrm{ZR}$ antibodies able to bind a broad spectrum of cytokinins [21]. After washing with $10 \mathrm{ml}$ of water, the immunoaffinity column was eluted with $4 \mathrm{ml}$ of ice-cold $100 \%$ methanol and immediately rinsed with water. The methanol eluate from the immunoaffinity column contained the cytokinin-free bases, ribosides, and $N$-glucosides. The cytokinin $O$-glucosides were not retained on the immunoaffinity column, and were eluted from the RPC18 column with $4 \mathrm{ml}$ of $80 \%$ methanol.

The cytokinin nucleotides which were bound to the DEAE Sephadex column, were eluted with $10 \mathrm{ml}$ of $1 \mathrm{M} \mathrm{NH}_{4} \mathrm{HCO}_{3}$. These were then retained on another RP-C18 column, and removed by eluting with $10 \mathrm{ml}$ of $80 \%$ methanol. The eluate was dried by rotary film evaporation and re-dissolved in $0.01 \mathrm{M}$ Tris. $\mathrm{HCl}(\mathrm{pH}$ 9). The cytokinin nucleotides were treated with alkaline phosphatase $\left(30 \mathrm{~min}, 37^{\circ} \mathrm{C}\right)$ and the resulting nucleosides were further purified by immunoaffinity chromatography as described above. Samples were stored at $-70^{\circ} \mathrm{C}$ until analysis by LC-MS/MS.

\subsection{High-performance liquid chromatography (HPLC)-UV spectrum} detection

Radioactive tracers $\left(\left[{ }^{3} \mathrm{H}\right]-\mathrm{ZR},\left[{ }^{3} \mathrm{H}\right]-\mathrm{Z}, 450 \mathrm{~Bq}\right.$ of each) were added to each sample to determine the recovery, and extraction and purification was performed as described above. The cytokinins were separated on a Microsorb C18 column $(150 \mathrm{~mm}, 4.6 \mathrm{~mm}$ i.d, $5 \mu \mathrm{m}$ particle size; Rainin, Woburn, MA) at a flow rate of $0.5 \mathrm{ml} / \mathrm{min}$ using a gradient of solvent $A$ ( $10 \%$ methanol in $40 \mathrm{mM}$ triethylammonium acetate, $\mathrm{pH} 3.35)$ and solvent $\mathrm{B}(80 \%$ methanol in $30 \mathrm{mM}$ acetic acid). The following gradient profile was used: $0 \mathrm{~min}, 90 \% \mathrm{~A}+10 \% \mathrm{~B} ; 20$ $\min , 50 \% \mathrm{~A}+50 \% \mathrm{~B} ; 39 \min , 45 \% \mathrm{~A}+55 \% \mathrm{~B} ; 40 \min 100 \% \mathrm{~B}[22]$. Fractions of $0.25 \mathrm{ml}$ were collected and $3 \mathrm{ml}$ of LSC cocktail (Ultimo Gold, Packard) was added for tritium counting (Tricarb 1500, Packard). Corrections for quenching of the radioactivity were made.

The UV absorbance between 240 and $300 \mathrm{~nm}$ was monitored on line with a diode array detector (Waters PDA991), with absorption at $268 \mathrm{~nm}$ being used for quantification. The identity of the eluting compounds was confirmed using the full-scale spectrum at the appropriate retention time. Recovery calculations were made via isotope dilution.
2.5. Quantitative analysis of cytokinins by electrospray tandem mass spectrometry

Cytokinin fractions were quantified by HPLC linked to a Quatro II mass spectrometer (Fisons) equipped with an electrospray interface ((+)ES LC-MS/MS). Ten-microliter samples were injected on a RPC8 column (Merck; LiChrosphere $60 \mathrm{RP}$ Select B; $5 \mu \mathrm{m} ; 125 \times 4 \mathrm{~mm}$ ) and eluted with methanol/0.01 $\mathrm{M}$ ammonium acetate $(70: 30, \mathrm{v} / \mathrm{v})$ at $800 \mu \mathrm{l} / \mathrm{min}$. Using a post-column split of $1 / 20$, the effluent was introduced into the electrospray source (source temperature $80^{\circ} \mathrm{C}$, capillary voltage $+3.5 \mathrm{kV}$, cone voltage $20 \mathrm{~V}$ ). Quantification was obtained by multiple reaction monitoring $(\mathrm{MRM})$ of $(\mathrm{MH})^{+}$and the appropriate product ion [23]. Endogenous concentrations were calculated, taking into account the abundance ratio of the diagnostic ions corresponding to the unlabelled and labelled (deuterated) compounds.

\subsection{Analysis of $A B A$ and $I A A$ by $G C-M S$}

Prior to GC-MS analysis the ABA and IAA samples were methylated with diazomethane [24], dried under nitrogen and stored at $-70^{\circ} \mathrm{C}$. GC-MS analysis was performed on a VG TRIO 2000 Mass Spectrometer (CI- mode) linked on line with a Hewlett Packard 5890 series II gas chromatograph equipped with a $14 \mathrm{~m}, 0.25 \mathrm{~mm}$ i.d., 0.25 rm DB1 stationary phase column. For ABA analysis, the following temperature gradient was used: $80-120^{\circ} \mathrm{C}\left(25^{\circ} \mathrm{C} / \mathrm{min}\right), 120-220^{\circ} \mathrm{C}$ $\left(15^{\circ} \mathrm{C} / \mathrm{min}\right), 220-300^{\circ} \mathrm{C}\left(40^{\circ} \mathrm{C} / \mathrm{min}\right)$. The diagnostic ions were at $\mathrm{m} / \mathrm{z}$ 278 and 280 corresponding to methyl-ABA and 180-methyl-ABA, monitored in single-ion monitoring (SIM) mode. After methylation, the IAA fractions were derivatized with heptafluorobuturyl imidazole (HFBI) [25]. GC-MS analysis was performed in the electron impact $(\mathrm{EI}+)$ mode with the following temperature gradient: $40-95^{\circ} \mathrm{C}\left(25^{\circ} \mathrm{C} /\right.$ min), $95-115^{\circ} \mathrm{C}\left(5^{\circ} \mathrm{C} / \mathrm{min}\right), 115-300^{\circ} \mathrm{C}\left(35^{\circ} \mathrm{C} / \mathrm{min}\right)$. The diagnostic ions were at $\mathrm{m} / \mathrm{z} 326$ and 332 corresponding to methyl-IAA-HFB and ${ }^{13} \mathrm{C}_{6}$-methyl-IAA-HFB, monitored in SIM.

\section{Results}

\subsection{Synchronization of the BY-2 cells}

To study the endogenous levels of cytokinins, IAA and of ABA during the cell cycle, a tobacco BY-2 cell suspension culture was synchronized using aphidicolin (see Section 2). Aphidicolin inhibits DNA polymerase $\alpha[26,27]$, and arrest the cells in early S-phase. Samples were taken immediately before $(0 \mathrm{~h})$ and at various intervals after the release of the cells from the aphidicolin block, and the levels of the various plant hormones were determined in the cells as well as in the growth medium. A peak of about $34 \%$ in the mitotic index was observed approximately $7 \mathrm{~h}$ after aphidicolin wash (Fig. 1A, 2A, and 3A). Independent experiments in which the levels of histone $\mathrm{H} 4$ mRNA were analyzed in synchronized BY-2 cultures that exhibited similar kinetics of the mitotic index, indicated that the $\mathrm{S}$ phase is completed $3 \mathrm{~h}$ after aphidicolin wash [28].

\subsection{Cytokinin levels in the synchronized cells}

Cytokinin levels were quantified in three independent experiments and by using two different methods, HPLC-UV spectrum detection and LC-MS/MS. Using HPLC-UV detection, we determined only the levels of zeatin type (Z-type) cytokinins, namely zeatin (Z), zeatin riboside (ZR) and zeatin riboside-5'-monophosphate (ZMP) (this experiment is referred to as Experiment 1). The levels of these cytokinins in the synchronized cells are presented in Fig. 1. Approximately 3 $\mathrm{h}$ after release of the cells from aphidicolin block, corresponding with the end of the $S$ phase, we observed an increase in the levels of $Z$ (peak value of $140 \mathrm{pmol} / \mathrm{gfw}$ ) and $\mathrm{ZR}$ (peak value of $120 \mathrm{pmol} / \mathrm{gfw}$ ). No change in ZMP levels was observed at this stage of the cell cycle. An increase in all three cytokinins coincided with the peak of the mitotic index: $Z$ (peak value of 

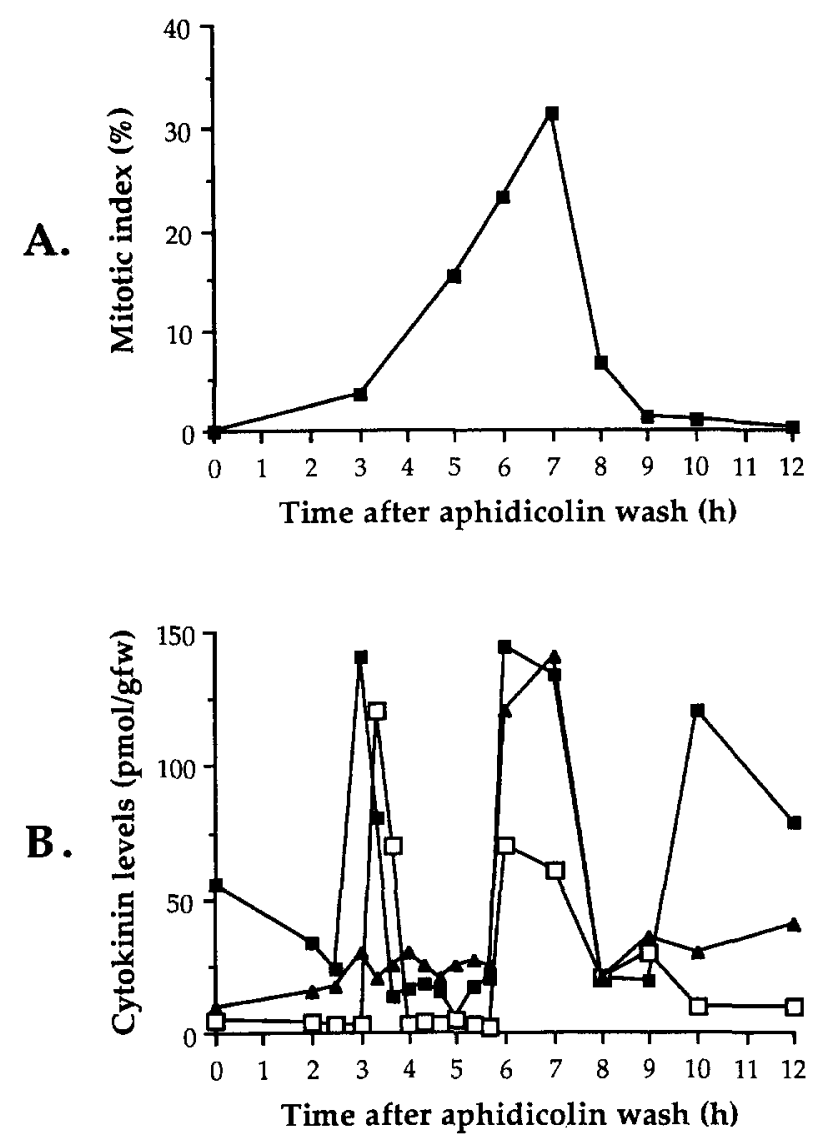

Fig. 1. Analyses of cytokinin levels in synchronized BY-2 cells by HPLC-UV spectrum detection (Exp. 1). (A) Mitotic index of the cells immediately before $(0 \mathrm{~h})$ and at different intervals after release from aphidicolin block. (B) Levels of Z ( $\square$ ), ZR ( $\square$ ) and ZMP ( $\Delta$ ) in the synchronized cells (concentrations in pmol/gfw of cells in a 4-ml sample).

$150 \mathrm{pmol} / \mathrm{gfw}$ ), ZR (peak value of $70 \mathrm{pmol} / \mathrm{gfw}$ ) and ZMP (peak value of $140 \mathrm{pmol} / \mathrm{gfw}$ ). Finally, at around $10 \mathrm{~h}$, corresponding to the Gl phase, a third increase in $\mathrm{Z}$ (peak value of $120 \mathrm{pmol} / \mathrm{gfw}$ ) was measured.

To study whether the levels of other cytokinins also fluctuate during the cell cycle, 16 different naturally occurring cytokinins were analyzed by means of MS. Two independent experiments are presented here and are referred to as Exps. 2 and 3 (Figs. 2 and 3, respectively). Among the cytokinins analyzed, those present in the cells at highest levels in both experiments were of the Z-type: Z, ZR, and ZMP. In Exp. 2, the levels of these cytokinins in the cells peaked at similar cell cycle phases compared with Exp. 1, in which the cytokinins were analyzed by HPLC-UV spectrum detection (Fig. 2B and $1 \mathrm{~B}$, respectively). Approximately $3 \mathrm{~h}$ after the release of the cells, a peak of $Z$ (peak value of $200 \mathrm{pmol} / \mathrm{gfw}$ ) and ZR (peak value of $80 \mathrm{pmol} / \mathrm{gfw}$ ) was detected, while ZMP levels were not changed. Coinciding with the peak in mitotic index, sharp increases in the levels of $Z$ (peak value of $290 \mathrm{pmol} / \mathrm{gfw}$ ), ZR (peak value of $90 \mathrm{pmol} / \mathrm{gfw}$ ) and ZMP (peak value of 350 $\mathrm{pmol} / \mathrm{gfw}$ ) were observed. Nine hours after the release, corresponding to the G1 phase, there was an increase in the level of $Z$ (peak value of 230 pmol/gfw). In Exp. 3 (Fig. 3), there was a higher variability in the levels of the Z-type cytokinins at the early stages of the cell cycle, that did not allow the identifica- tion of clear peaks at the end of the S phase, and no peak in $\mathrm{Z}$ levels could be detected at the G1 phase. Similar to the previous experiments, the levels of all three cytokinins increased coinciding with the peak of mitotic index, although the relative abundance of ZR and ZMP was different (Fig. 3B): Z (peak value of $240 \mathrm{pmol} / \mathrm{gfw}$ ), ZR (peak value of $500 \mathrm{pmol} /$ gfw), and ZMP (peak value of $85 \mathrm{pmol} / \mathrm{gfw}$ ).

Analyses of dihydrozeatin-type (DZ-type) cytokinins in the synchronized cells (Fig. 2C and 3C) indicated that these compounds were present at lower levels compared to the Z-type cytokinins (note the different scales in part $B$ and $C$ of each figure). In Exp. 2, and much less pronounced in Exp. 3, there was an increase in dihydrozeatin riboside (DZR) levels at the end of the $S$ phase. During the peak of mitotic index there was an increase in the levels of dihydrozeatin (DZ) and of DZR, and in Exp. 2 also of dihydrozeatin riboside- $5^{\prime}$-monophosphate (DZMP).

In both Exps. 2 and 3, the levels of the cytokinin $N$ - and $O$-glucosides analyzed were either very low or did not change significantly in cells at different phases of the cell cycle (data not shown). Zeatin- $N$-glucoside (ZNG) and dihydrozeatin- $N$ glucoside (DZNG) concentrations were close to or under the detection limit of $1 \mathrm{pmol} / \mathrm{gfw}$. The levels of zeatin- $O$-glucoside (ZOG) and dihydrozeatin- $O$-glucoside (DZOG) were approximately 30 and $15 \mathrm{pmol} / \mathrm{gfw}$, respectively, throughout the entire cell cycle. The levels of zeatin riboside- $O$-glucoside (ZROG) and dihydrozeatin riboside- $O$-glucoside (DZROG) were close to or under the detection limit of $4 \mathrm{pmol} / \mathrm{gfw}$. In addition, no significant changes in the levels of endogenous isopentenyladenine-type (iP-type) cytokinins could be identified in the cells (data not shown). The steady-state concentration of isopentenyladenine (2iP) was around $15 \mathrm{pmol} / \mathrm{gfw}$. The levels of isopentenyladenosine (2iPR) and isopentenyladenine$\mathrm{N}$-glucoside (2iPNG) were close to the detection limit of 3 $\mathrm{pmol} / \mathrm{gfw}$, whereas isopentenyladenosine-5'-monophosphate (2iPMP) levels were below the detection limit of $2 \mathrm{pmol} / \mathrm{gfw}$.

In all three experiments, the levels of cytokinins detected in the growth medium of the synchronized cells were close to or below the detection limit $(\sim 0.5-5 \mathrm{pmol} / \mathrm{ml}$ medium for the 16 different cytokinins analyzed) (data not shown), and no significant change in the levels of any of these cytokinins in the medium could be detected in the course of culture synchronization.

\subsection{Analyses of IAA and ABA levels during culture synchronization}

No significant change could be observed in the cellular levels of IAA during culture synchronization, which ranged around $50 \mathrm{pmol} / \mathrm{gfw}$ (data not shown). ABA levels ranged around $40 \mathrm{pmol} / \mathrm{gfw}$ until $4 \mathrm{~h}$ after release from aphidicolin block and were below the detection limit thereafter (data not shown). The levels of IAA in the cell culture medium were close to or below the detection limit $(0.5 \mathrm{pmol} / \mathrm{ml})$, and similarly no ABA could be detected in the cell culture medium (detection limit of $0.5 \mathrm{pmol} / \mathrm{ml}$ ) (data not shown).

\section{Discussion}

Correlation between cell cycle progression and endogenous levels of plant hormones was studied in synchronized tobacco BY-2 cell suspension cultures. No significant correlation could be identified for IAA and ABA, whose levels remained rather 

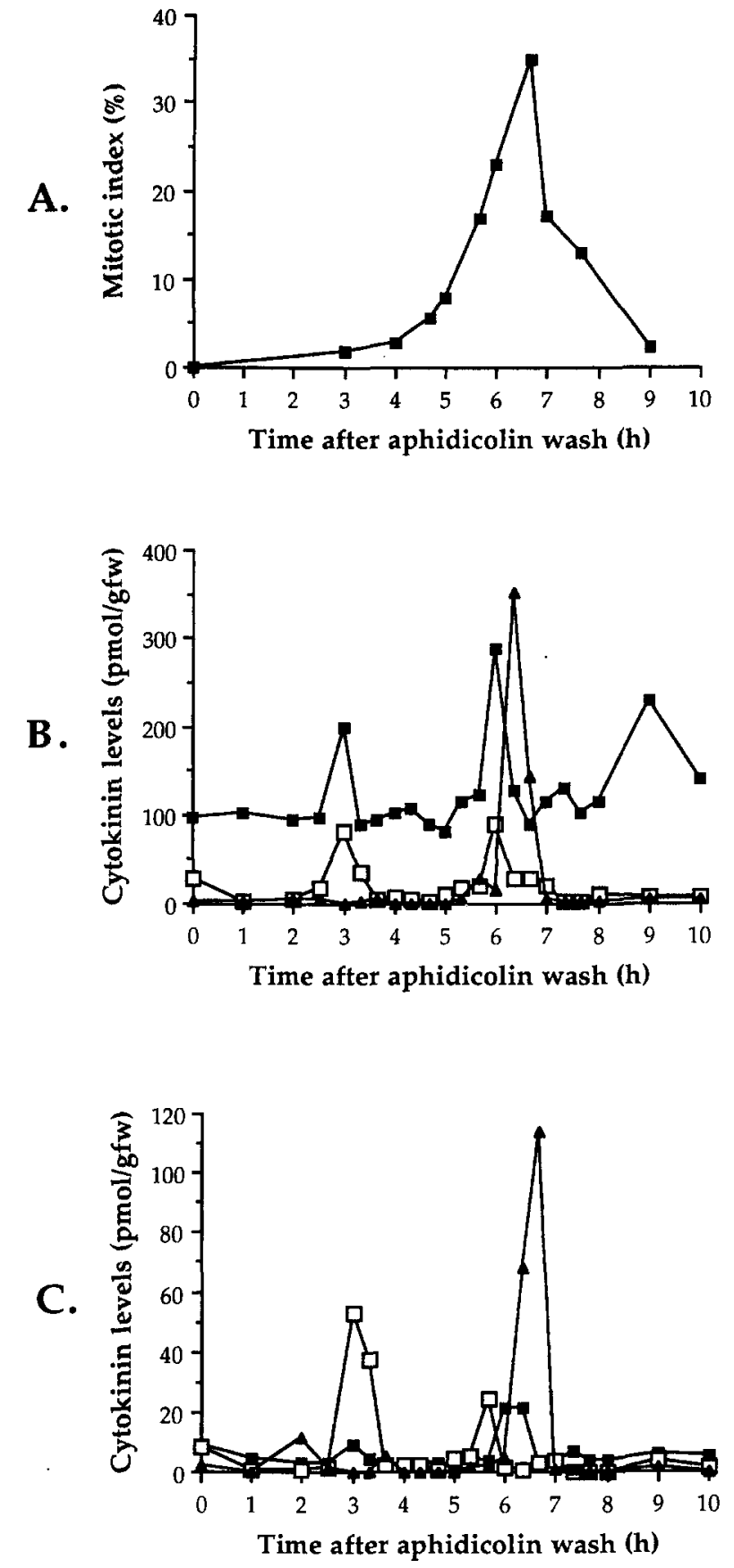

Fig. 2. Analyses of cytokinin levels in synchronized BY-2 cells by LC-mass spectrometry (Exp. 2). (A) Mitotic index of the cells immediately before $(0 \mathrm{~h})$ and at different intervals after release from aphidicolin block. (B) Levels of Z ( $\square$ ), ZR ( $\square$ ) and ZMP ( $\Delta$ ) in the synchronized cells (concentrations in pmol/average gfw of cells in a 4-ml sample). (C) Levels of DZ ( $\square$ ), DZR ( $\square)$ and DZMP ( $\Delta$ ) in the synchronized cells.

low. Apparently BY-2 cells do not contain sufficient endogenous auxins to sustain their growth, as they are unable to divide in the absence of exogenous 2,4-D [29]. In contrast, we observed sharp peaks in the levels of specific cytokinins at specific phases of the cell cycle. Among the cytokinins analyzed, cell cycle-dependent fluctuations were identified only for the Z-type (Z, ZR, and ZMP) and for their dihydro derivates, but the magnitude of the peaks in the second group was lower.
Sharp peaks in the levels of Z, ZR and DZR were correlated with the end of the $S$ phase (around $3 \mathrm{~h}$ after release of the cells from aphidicolin block). In one of the three experiments presented here (Exp. 3), no significant change could be identified in the levels of $\mathrm{Z}$ and $\mathrm{ZR}$ at this stage. It is possible that putative peaks were missed due to the short duration of the increases in cytokinins levels in the course of synchronous growth. The occurrence of a small peak in DZR levels $3 \mathrm{~h}$ after release also in Exp. 3 supports this possibility.

During mitosis, the levels of $Z, Z R$, and ZMP peaked in all three experiments, although to different levels. Thus, while $Z$ peaked to comparable levels in all three experiments, the peak of ZMP was higher than that of ZR in Exps. 1 and 2, while the opposite was seen in Exp. 3. This variation in the relative abundance of the nucleotide and riboside form of $\mathrm{Z}$ is coherent with the fact that these forms are interconvertable, but further study is required to know whether the physiological role of these compounds is similar, and which factors determine their relative abundance. It is also interesting to note that in Exp. 1, in which the peak of mitotic index was broad compared to Exps. 2 and 3, the duration of the cytokinins peaks at this stage was also prolonged. The levels of the DZtype cytokinins, that are formed by reduction of the zeatin side chains, were also increased at this stage of the cell cycle, to levels that were lower than, but proportional to, their corresponding Z-type cytokinin. In Exp. 3, in which the peak in ZMP levels during mitosis was rather low, no increase in DZMP levels could be detected.

Although in two of the three experiments an increase in $\mathrm{Z}$ levels was observed during the G1 phase, following the decrease of the mitotic index, further experiments need to confirm this.

Cytokinin $O$-glucosides are considered as a pool of biologically inactive forms, that can be deglucosylated to release an active cytokinin and vice versa, while $N$-glucosides are extremely stable and may be important in regulating levels of active cytokinin through inactivation [30]. The cytokinin glucosides analyzed in this study (ZOG, DZOG, ZROG, DZROG, $\mathrm{ZNG}$, and DZNG) were present at low and non-fluctuating levels throughout the entire cell cycle. Thus, the sharp increases in the levels of $\mathrm{Z}, \mathrm{DZ}, \mathrm{ZR}$, and DZR at different stages of the cell cycle most probably results from their de novo synthesis and not from hydrolysis of their $O$-glucoside. Similarly, the sharp subsequent decrease in the levels of these cytokinins is not the result of inactivation by $O$-glucosylation, and at least for $\mathrm{Z}$ and $\mathrm{DZ}$ is also not a result of $\mathrm{N}$-glucosylation. At present the only plant enzyme known to catalyze the degradation of cytokinins to inactive products that lack the side-chain is cytokinin oxidase [31]. This enzyme cannot accept cytokinin nucleotides as substrate and thus may only account for the rapid decrease in the levels of $Z, D Z, Z R$, and DZR. ZMP and DZMP need first to be dephosphorylated to become a substrate for cytokinin-oxidase.

An increase in cytokinin content at late $S$ phase and during mitosis was also demonstrated by Nishinari and Syoni [32] using synchronized suspension cultures of the Nicotiana tabacum L. cv. Xanthi cell strain XD6S. They measured concentrations of only two cytokinins by thin layer chromatography, namely $\mathrm{Z}$ and $\mathrm{ZR}$. As far as we are aware, the present study is the first in which 16 different naturally occurring cytokinins, as well as ABA and IAA, were simultaneously identified and quantified in synchronized plant cells by MS analysis with 

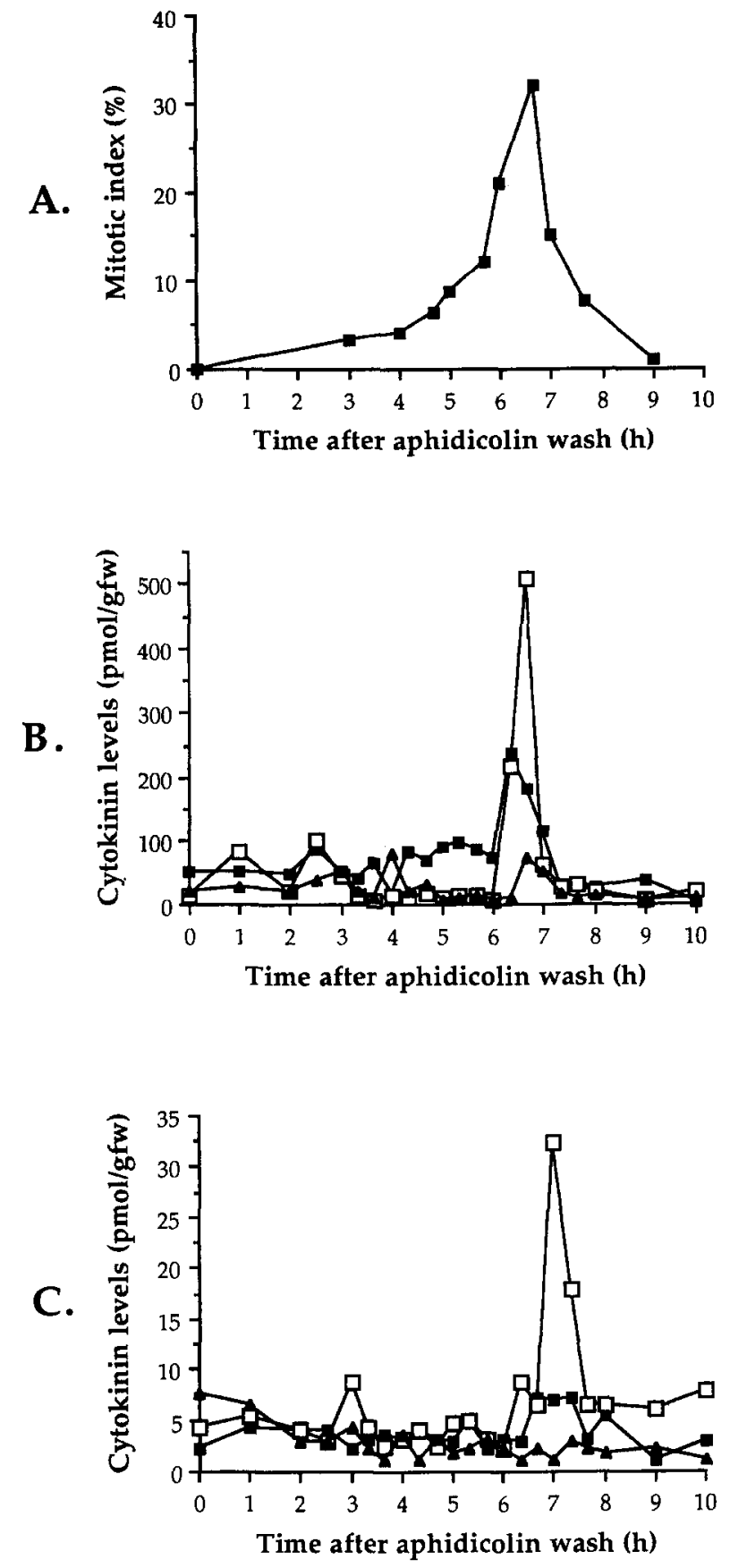

Fig. 3. Analyses of cytokinin levels in synchronized BY-2 cells by LC-mass spectrometry (Exp. 3). For details, see legend to Fig. 2.

detection limits of $\sim 1 \mathrm{pmol} / \mathrm{gfw}$. The combination of immunoaffinity purification and solid-phase extraction allowed the identification of these hormones in very small quantities of cells $(\sim 0.25 \mathrm{gfw})$.

Functional assays have suggested the involvement of cytokinins in the passage through several restriction points of the plant cell cycle. Cytokinins were found to be necessary for the entry of tobacco mesophyll protoplasts into $S$ phase [10] and for the G2/M transition of tobacco and Glycine max suspension cultures $[9,11]$. Crowell and Salaz [33] have shown that the growth of tobacco BY-2 cells is inhibited by low concentrations of lovastatin, which inhibits the isoprenoid pathway that leads to the biosynthesis of the cytokinin side chain. This inhibition could be reversed by supplying $\mathrm{Z}$ to the medium. These data support our suggestion that fluctuations in the levels of specific cytokinins at distinct stages of the cell cycle reflect their essential role during these phases. The question what is the nature of this role needs further study. As cytokinins are adenine analogues, one hypothesis to explain their action could be interfering with the activity of specific cell cycle-regulatory protein kinases at distinct points of the cell cycle. Such activity was recently shown for the cytokinin analogue olomoucine (2-(2-hydroxyethylamino)-6-benzylamino-9methylpurine). It was shown that olomoucine, acting as a competitive inhibitor for ATP binding, specifically inhibits the activity of certain CDK-cyclin complexes and MAP kinases in vitro, while other protein kinases and CDK complexes, or even complexes of the same CDK with another cyclin, were not affected by low concentrations of this drug [34]. Analysis of CDK2/olomoucine crystals showed that the purine group of olomoucine is located in the pocket where ATP binds to CDK2 [35]. In vivo, olomoucine blocks plant cells at the G1/S and G2/M transitions [36]. Thus, according to this hypothesis, the general structure of the molecule (a specific cytokinin or a synthetic analogue such as olomoucine) may determine its specificity to certain CDK-cyclin complexes, or to other kinases, such as MAP kinases or the kinases that regulate CDK activity. All of these regulatory kinases need to be active only at restricted phases of the cell cycle and to be inactivated immediately thereafter. We are currently investigating whether specific cytokinins could actually interfere with the activity of plant CDK-cyclin complexes.

Acknowledgements: The authors wish to thank N. Schrijvers for expert technical assistance and W. Van Dongen for LC-MS/MS analyses. This work was supported by grants from the Belgian Programme on Interuniversity Poles of Attraction (Prime Minister's Office, Science Policy Programming, \#38), the Fonds voor Kollektief Fundamenteel Onderzoek (G.0121.96), the Vlaams Actieprogramma Biotechnologie (ETC 002), and the Körber Stiftung. O.S. is indebted to the Rothschild Foundation and the European Molecular Biology Organization for fellowships. P.R, and H.V.O. are a Research Assistant and a Research Director of the National Fund for Scientific Research (Belgium), respectively. D.I. is a Research Director of the Institut National de la Recherche Agronomique (France).

\section{References}

[1] Jacobs, T.W. (1995) Annu. Rev. Plant Physiol. Plant Mol. Biol. 46, 317-339.

[2] Shaul, O., Van Montagu, M. and Inzè, D. (1996) Crit. Rev. Plant Sci. $15,97-112$.

[3] Meyer, Y. and Cooke, R. (1979) Planta 147, 181-188.

[4] Miller, C.O., Skoog, F.S., Okumura, M.H., von Saltza, H. and Strong, F.M. (1955) J. Am. Chem. Soc. 77, 1392.

[5] Mok, D.W.S. and Mok, M.C. (1994) Cytokinins. Chemistry, Activity and Function. CRC Press, Boca Raton, FL.

[6] Davies, P.J. (1995) in: Plant Hormones. Physiology, Biochemistry and Molecular Biology (Davies, P.J., ed.) pp. 7-16, Kluwer, Dordrecht.

[7] Skoog, F. and Miller, C. (1957) Soc. Exp. Biol. Symp. 11, 188231.

[8] Phillips, I.D.J. (1975) Annu. Rev. Plant Physiol. 26, 341-352.

[9] Fosket, D.E., Volk, M.J. and Goldsmith, J. (1977) Plant Physiol. $60,554-561$.

[10] Cooke, R. and Meyer, Y. (1981) Planta 152, 1-7.

[11] Jouanneau, J.P. and Tandeau de Marsac, N. (1973) Exp. Cell. Res. 77, 167-174.

[12] Barlow, P.W. and Pilet, P.E. (1984) Physiol. Plant. 62, 125-132.

[13] Banerjee, S.N. (1968) Plant Cell Physiol. 9, 577-583. 
[14] Appelbaum, A. and Burg, S.P. (1972) Plant Physiol. 50, 117-124.

[15] Pfosser, M., Köningshofer, H. and Kandeler, R. (1990) J. Plant Physiol. 136, 574-580.

[16] Nagata, T., Nemoto, Y. and Hasezawa, S. (1992) Int. Rev. Cytol. $132,1-30$.

[17] Gray, R.T., Mallaby, R., Ryback, G. and William, V.P. (1974) J.C.S. Perkin II, 919-924.

[18] Bieleski, R.L. (1964) Anal. Biochem. 9, 431-442.

[19] Ulvskov, P., Marcussen, J., Seiden, P. and Olsen, C.E. (1992) Planta 188, 182-189.

[20] Redig, P., Prinsen, E., Van Dongen, W. and Van Onckelen, H. (1992) Physiol. Plant. 5, A29.

[21] Ulvskov, P., Nielsen, T., Seiden, P. and Marcussen, J. (1992) Planta 188, 70-77.

[22] Goicoechea, N., Dolezal, K., Antolin, M.C., Strnad, M. and Sanchez-Diaz, M. (1995) J. Exp. Bot. 46, 1543-1549.

[23] Prinsen, E., Redig, P., Van Dongen, W., Esmans, E. and Van Onckelen, H. (1995) Rapid Commun. Mass Spectrom. 9, 948 953.

[24] Schlenk, H. and Gellerman, J.-L. (1960) Anal. Chem. 32, 14121414.

[25] Pilet, P.-E. and Saugy, M. (1985) Planta 164, 254258.
[26] Ikegami, S., Taguchi, T., Ohashi, M., Nagano, H. and Mano, Y. (1978) Nature 275, 458-460.

[27] Sala, F., Parisi, B., Amileni, G., Pedrali-Noy, G. and Spadari, S. (1980) FEBS Lett. 117, 93-98.

[28] Shaul, O., Mironov, V., Burssens, S., Van Montagu, M. and Inzè, D. (1996) Proc. Natl. Acad. Sci. USA 93, 4868-4872.

[29] Ishida, S., Takahashi, Y. and Nagata, T. (1993) Proc. Natl. Acad. Sci. USA 90, 11152-11156.

[30] Sembdner, G., Atzorn, R., and Schneider, G. (1994) Plant Mol. Biol. 26, 1459-1481.

[31] Hare, P.D. and van Staden, J. (1994) Physiol. Plant. 91, 128-136.

[32] Nishinari, N. and Syono, K. (1986) Plant Cell Physiol. 27, 147153.

[33] Crowell, D.N. and Salaz, M.S. (1992) Plant Physiol. 100, 2090 2095.

[34] Vesely, J., Havlicek, L., Strnad, M., Blow, J.J., Donella-Deana, A., Pinna, L., Letham, D.S., Kato, J., Detivaud, L., Leclerc, S. and Meijer, L. (1994) Eur. J. Biochem. 224, 771-786.

[35] Schulze-Gahmen, U., Brandsen, J., Jones, D.H., Morgan, D.O., Meijer, L., Vesely, J. and Kim, S.-H. (1995) Proteins 22, 378-391.

[36] Glab, N., Labidi, B., Qin, L., Trehin, C., Bergonioux, C. and Meijer, L. (1994) FEBS Lett. 353, 207-211. 